\title{
Computer held chronic disease registers in general practice: a validation study
}

\author{
ANGELA COULTER, ${ }^{1}$ SUSAN BROWN, ${ }^{2}$ AND ANGELA DANIELS 3 \\ From ${ }^{1}$ the Unit of Clinical Epidemiology, University of Oxford; ${ }^{2}$ the Department of Community Medicine, St. \\ Leonard's, Nuttall Street, London N1; and ${ }^{3}$ the Oxford Regional Health Authority, Headington, Oxford.
}

ABSTRACT Lists of patients receiving repeat prescriptions for epilepsy, diabetes, thyroid disease and asthma were compared with chronic disease registers stored on seven practice computers. Diabetes was the most accurately recorded disease: the names of $72 \%$ of patients receiving medication for this condition appeared on the relevant disease registers. Agreement between the two data sources was $68 \%$ for thyroid disease, $58 \%$ for asthma and $49 \%$ for epilepsy. The levels of accuracy are not yet high enough for the computerised chronic disease registers to provide an accurate estimate of the prevalence of these conditions, but new system developments suggest a more optimistic outlook for the future.

The advent of computers into general practice has potentially far reaching implications for the improvement of public health. Computerisation offers the general practitioner a valuable tool with which to organise preventive programmes and anticipatory care, to monitor the health of his or her practice population and to audit and review clinical practice. ${ }^{1-7}$ As these advantages have become increasingly evident and a variety of specially designed general practice software systems have become available at reasonable or no cost, ${ }^{8}$ more and more general practitioners have decided to take the plunge into computerisation. For the epidemiologist and health planner these developments hold out the hope that the pooled records from computerised practices will provide a comprehensive profile of patterns of morbidity in the population. ${ }^{9}$ How realistic are these aspirations?

General practitioners in the Oxford region have been pioneering the use of computers in their practices since 1970, when the Oxford Community Health Project was established as a collaborative venture between Oxford Regional Health Authority and the Oxford University Unit of Clinical Epidemiology. At its inception it was hoped that once the computing systems were established, the pooled general practice data would provide planners in the Region with a means of assessing future demand for hospital care, as well as providing the basis for epidemiological studies. Participating practices were therefore encouraged to establish registers of patients with common chronic diseases.

When the Oxford Community Health Project was first established about 35 practices used the general practice system developed on the Regional Computer Unit's mainframe computer, which involved a batch system of data entry. The facilities were provided free of charge to the practices. Since then general practice systems have become widely available on microcomputers and many practices have transferred their data to their own within practice systems. Currently about one third of the 360 practices in the region have access to computing systems, either the mainframe system or practice based micros, and a further third report plans to instal micro systems in the future. ${ }^{10}$

Many practices have used their computing facilities to develop chronic disease registers. These disease registers can be used to assist in the management and monitoring of patients with common chronic conditions and to provide a basic morbidity profile of the practice. However, an earlier validation study by Mant and Tulloch, who looked at the registers established in four practices of patients with diabetes, epilepsy, hypertension, myocardial infarction, thyroid disease and malignancy, and compared them with lists of patients discharged from hospital with these diagnoses, found that they were incomplete. ${ }^{11}$ This study had analysed data recorded in 1982 to 1984 and used as its benchmark lists from Hospital Activity Analysis records selected by primary and secondary diagnosis and by general practitioner code.

By 1987 the practices which participated in this earlier study had accumulated considerably more experience of using computers and might therefore be expected to have improved on these levels of completeness of data recording, so it was decided to 
repeat the validation study, this time using a different "gold standard" and involving more practices.

\section{Methods}

The gold standard adopted was repeat prescriptions. Seven practices which had established chronic disease registers or patient summaries, and used computers to issue repeat prescriptions, agreed to participate. The British National Formulary ${ }^{12}$ was used to produce a list of medications commonly prescribed for patients suffering from epilepsy (anti-epileptics), diabetes mellitus (insulins and oral hypoglycaemic drugs), thyroid disorders (thyroid hormones and antithyroid preparations) and asthma (bronchodilators, inhaled corticosteroids and prophylactic drugs). General practitioners in these practices were asked to select those drugs they normally prescribed exclusively to these patients, who could then be assumed to have the disease for which they should be on the chronic disease register. Medications prescribed for more than one type of medical condition were therefore excluded. For this reason it was not possible to study the same list of diseases as in the earlier study. For example, hypertension had to be excluded from our study because many of the medications prescribed for these patients are also prescribed for other conditions. Only current prescriptions were considered so it was not possible to check the patients who remained on the disease register but who were no longer on medication. Lists of names of patients receiving each of these preparations on a repeat basis were produced using the practice computers, and compared with the computer printouts of patients on the chronic disease registers.

\section{Results}

Three of the participating practices $(1,4$ and 6$)$ had participated in the earlier study by Mant and Tulloch and four had not. Six practices had their own microcomputer systems running VAMP software and one (6) used the Oxford Community Health Project mainframe system. All had at least four years' experience of computerisation and partners in all practices were involved in teaching and research. List sizes of these practices ranged from 6000 to 22000 , the combined total population being 76660 .

Tables 1 to 4 give the results for the four chronic diseases selected for study. Patients on long term medication for diabetes were most likely to be recorded on the relevant chronic disease register. Five out of the seven practices achieved a registration rate of more than $90 \%$ of those on medication for this condition. However in one practice only $18 \%$ of the patients receiving long term medication for diabetes appeared on the diabetes register. The registers for the
Table 1 Computer held epilepsy registration

\begin{tabular}{lccccc}
\hline & $\begin{array}{l}\text { Number of patients } \\
\text { on register }\end{array}$ & $\begin{array}{l}\text { Number of patients } \\
\text { on long term } \\
\text { medication }\end{array}$ & $\begin{array}{l}\text { Number (\%) of patients on } \\
\text { long term medication } \\
\text { and recorded on register }\end{array}$ \\
\hline Practice & 1 & 47 & 52 & 27 & $(52)$ \\
& 2 & 29 & 46 & 14 & $(30)$ \\
& 3 & 74 & 65 & 30 & $(46)$ \\
& 4 & 53 & 20 & 15 & $(75)$ \\
& 5 & 107 & 115 & 61 & $(53)$ \\
& 6 & 48 & 32 & 25 & $(78)$ \\
& 7 & 69 & 76 & 28 & $(37)$ \\
Total & 427 & 406 & 200 & $(49)$ \\
\hline
\end{tabular}

Table 2 Computer held diabetes registration

\begin{tabular}{|c|c|c|c|c|}
\hline \multirow[b]{2}{*}{$\begin{array}{r}\text { Practice } 1 \\
2 \\
3 \\
4 \\
5 \\
6 \\
7\end{array}$} & \multirow{2}{*}{$\begin{array}{l}\text { Number of patients } \\
\text { on register } \\
99 \\
73 \\
149 \\
91 \\
109 \\
98 \\
42\end{array}$} & \multirow{2}{*}{$\begin{array}{l}\text { Number of patients } \\
\text { on long term } \\
\text { medication }\end{array}$} & \multicolumn{2}{|c|}{$\begin{array}{l}\text { Number }(\%) \text { of patients on } \\
\text { long term medication } \\
\text { and recorded on register }\end{array}$} \\
\hline & & & $\begin{array}{r}54 \\
21 \\
59 \\
32 \\
137 \\
60 \\
17\end{array}$ & $\begin{array}{l}(96) \\
(95) \\
(55) \\
(97) \\
(90) \\
(92) \\
(18)\end{array}$ \\
\hline Total & 661 & 530 & 380 & (72) \\
\hline
\end{tabular}

Table 3 Computer held thyroid registration

\begin{tabular}{llllll}
\hline \multicolumn{1}{c}{$\begin{array}{l}\text { Number of patients } \\
\text { on register }\end{array}$} & $\begin{array}{l}\text { Number of patients } \\
\text { on long term } \\
\text { medication }\end{array}$ & $\begin{array}{l}\text { Number (\%) of patients on } \\
\text { long term medication } \\
\text { and recorded on register }\end{array}$ \\
\hline Practice & 1 & 78 & 92 & 67 & $(73)$ \\
& 2 & 64 & 63 & 44 & $(70)$ \\
& 3 & 119 & 69 & 58 & $(84)$ \\
& 4 & 66 & 20 & 14 & $(70)$ \\
& 5 & 123 & 64 & 36 & $(42)$ \\
& 6 & 70 & 53 & 4 & $(68)$ \\
Total & 7 & 64 & 5 & 250 & $(68)$ \\
\hline
\end{tabular}

Table 4 Computer held asthma registration

\begin{tabular}{llllll}
\hline & $\begin{array}{l}\text { Number of patients } \\
\text { on register }\end{array}$ & $\begin{array}{l}\text { Number of patients } \\
\text { on long term } \\
\text { medication }\end{array}$ & $\begin{array}{l}\text { Number (\%) of patients on } \\
\text { long term medication } \\
\text { and recorded on register }\end{array}$ \\
\hline Practice & 1 & 442 & 335 & 242 & $(72)$ \\
& 2 & 220 & 323 & 161 & $(50)$ \\
& 3 & 417 & 328 & 212 & $(65)$ \\
& 4 & 130 & 126 & 42 & $(33)$ \\
& 5 & 666 & 496 & 290 & $(58)$ \\
& 6 & 169 & 163 & 85 & $(52)$ \\
Total & 7 & 399 & 428 & 236 & $(55)$ \\
\hline
\end{tabular}

other conditions were less complete. All but one of the practices had registered two thirds of those receiving repeat prescriptions for thyroid disorders, but only two practices had achieved this level of completeness for epilepsy and asthma. None of the practices managed to achieve high registration levels for all patients on medication for these four conditions, but none was consistently low.

\section{Discussion}

The main conclusion we would draw from these results is that the systems in use in these practices for 
registering patients with chronic diseases were not accurate enough to give a reliable estimate of the prevalence of these conditions. Since these practices were experienced computer users, this finding will be somewhat depressing for those hoping that the advent of general practice computerisation had ushered in a new era of readily accessible data on patterns of morbidity in the community.

It is just possible that part of the discrepancy between the prescription lists and the disease registers might be explained by a failure to isolate completely the prescriptions for one condition. This may have occurred in the case of asthma, where it is possible that patients receiving therapy for chronic obstructive airways disease or hay fever might quite reasonably not be considered eligible for the chronic disease register. This in turn highlights the definitional problems inherent in any assessment of the prevalence of these conditions.

Comparisons with Mant and Tulloch's earlier validation study are not straightforward because of the different methods adopted and the different conditions studied. However the results follow a similar pattern in that they also found that patients with diabetes were more reliably recorded on the chronic disease registers $(72 \%$ agreement between their two data sources) and that recording of other diseases, with the exception of hypertension for which they found $69 \%$ agreement, was less reliable. They surmised that general practitioners were more convinced of the value of regular monitoring of their diabetic and hypertensive patients and were therefore more likely to make the effort to record these conditions.

All practices involved in this study were experienced computer users, although it is probable that not all partners in each practice shared the same degree of enthusiasm for data recording. In a busy general practice, no matter how well motivated, it is easy to see how morbidity recording which requires a separate entry from that on the individual patient notes can get overlooked. All the practices used their computer systems as an adjunct to, rather than a substitute for, the manual records. All diagnostic data therefore had to be recorded twice, though not necessarily by the general practitioner involved; and since the general practitioners hardly ever used the computer during consultations, data entry did not occur at the time of diagnosis.

General practice micro systems are becoming faster and easier to use and general practitioners and practice staff are becoming more experienced in their use. It is likely that use during consultations will increase. Early predictions that this development would have an adverse effect on doctor-patient communications appear to be unfounded. ${ }^{13}$ Software system improvements include prompts which, for example, require a morbidity code to be entered before a prescription can be issued. The "no cost" general practice computing systems offered by VAMP and AAH Meditel, which are aiming to collect data on morbidity as well as acute and repeat prescribing, are encouraging the use of terminals on each partner's desk in order to facilitate accuracy and completeness of recording. ${ }^{14}$

It is likely that general practitioners will eventually find it easier to use the computer as the main patient record and once this stage has been reached we can expect levels of accuracy and completeness to improve dramatically. However in order for these pooled data to be useful for epidemiological and planning purposes there will need to be agreement on diagnostic definitions. ${ }^{15}$ Date of first diagnosis will also be an essential requirement if the data are to be used to determine incidence rates.

These problems are not insurmountable, but it is probably wise to remain cautiously hopeful at this stage. The perfect morbidity database is not yet available and computerised systems cannot yet compete with the specially designed surveys of morbidity in general practice. ${ }^{16}$ However it is beginning to be more likely that within the next few years it will be possible to obtain a profile of patterns of illness in the community without resorting to special surveys involving manual recording.

We thank the general practitioners in Berinsfield, Shipston-on-Stour, Sonning Common, Thatcham, Newport Pagnell, West Street, Chipping Norton and Beaumont Street, Oxford for their participation in this study. The Unit of Clinical Epidemiology is part of the University of Oxford Department of Community Medicine and General Practice, and is funded by the Department of Health and the Oxford Regional Health Authority.

Address for correspondence and reprints: Ms Angela Coulter, Primary Care Research Officer, Oxford Regional Health Authority, Old Road, Headington, Oxford OX3 7LF.

\section{References}

${ }^{1}$ Royal College of General Practitioners Computer Working Party. Computers in primary care (Occasional Paper 13). London: RCGP, 1980.

2 Akerman F. Surgery computer: a quiet revolution for general practice. Br Med J 1984; 288: 1049-53.

${ }^{3}$ Roland MO, Zander LI, Evans M, Morris R, Savage RA. Evaluation of a computer assisted repeat prescribing programme in a general practice. $\mathrm{Br}$ Med $J$ 1985; 291: 456-8.

${ }^{4}$ Fitter MJ, Evans AR, Garber JR. Computers and audit. $J$ $R$ Coll Gen Pract 1985; 35: 522-4. 
${ }^{5}$ Difford F. A computerised audit of a screening programme to establish rubella immunity. $J R$ Coll Gen Pract 1986; 36: 371-2.

${ }^{6}$ Difford F, Telling JP, Davies KR, Fornear JE, Reading CA. Continuous opportunistic and systematic screening for hypertension with computer help: analysis of nonresponders. Br Med J 1987; 294: 1130-2.

${ }^{7}$ Sanderson H. Potential benefits for patient care from computing. Community Med 1987; 9: 238-46.

${ }^{8}$ Daniels A, Coulter A. How to choose a general practice computing system: comparison of commercial packages. Br Med J 1988; 297: 838-40.

${ }^{9}$ Coulter A. Measuring morbidity. Br Med J 1987; 294: 263-4.

${ }^{10}$ Coulter A. The Oxford Community Health Project Oxford: University of Oxford Unit of Clinical Epidemiology, 1988.

${ }^{11}$ Mant D, Tulloch A. Completeness of chronic disease registration in general practice. $B r$ Med $J$ 1987; 294: 223-4.
${ }^{12}$ British Medical Association/Pharmaceutical Society of Great Britain. British National Formulary 1987. London: BMA, Pharmaceutical Press, 1987.

${ }^{13}$ Rethans J, Hoppener P, Wolfs G, Diederiks J. Do personal computers make doctors less personal? Br Med J 1988; 296: 1446-8.

${ }^{14}$ Royal College of General Practitioners. Advice to members considering the current 'no cost' computer systems. RCGP, December 1987.

${ }^{15}$ Fairley $R$. Compiling a practice disease register-the prevalence of incidental problems. J R Coll Gen Pract 1984; 34: 213-5.

${ }^{16}$ Royal College of General Practitioners, Office of Population Censuses and Surveys, Department of Health and Social Security. Morbidity statistics from general practice 1981-82. London: HMSO, 1986.

Accepted for publication September 1988 